\title{
PAPR OFDM Reduction Technique Using Clipping Filtering Method
}

\author{
Rachmad Saptono ${ }^{1}$, Farida Arinie Soelistianto ${ }^{2}$, Martono Dwi Atmadja ${ }^{3}$ \\ 1,2,3 ${ }^{2}$ ecturer, Electrical Engineering, Malang State Polytechnic, Malang, Indonesia
}

\begin{abstract}
Orthogonal frequency division multiplexing (OFDM) is a transmission technique widely used by various wireless communication technologies. The OFDM system still has a weakness, which is the high value of the peak to average power ratio (PAPR). The high PAPR value causes inefficient use of power amplifiers (PA). With this incident, a more effective way is needed to reduce the PA, namely by using a pre-distorter on the OFDM signal before entering the high power amplifier (HPA). The purpose of decreasing the PAPR value is to compensate for the nonlinearity of the HPA and simultaneously improve system performance. The value of the input signal strength that is close to the PA nonlinear saturation region will experience nonlinear distortion and result in a worse system. A decrease in the PAPR value will be carried out to reduce the signal that has a large amplitude from the possibility that could occur. Therefore, in this OFDM system, a clipping filtering technique will be used, with the value of the clipping ratio (CR) to produce the PAPR0 value, through the CCDF (Complementary Cumulative Distribution Function) curve. The results of the study using a Clipping Filtering to determine the minimum PAPR reduction value in the form of a CCDF (Complementary Cumulative Distribution Function) curve with a predetermined Clipping Ratio (CR) value parameter, the results of observing the probability of PAPR > PAPR0 are 10-4 on an OFDM transmitter system without reduction (OFDM) produces a PAPR0 value of $9,727 \mathrm{~dB}$.
\end{abstract}

Keywords: OFDM, PAPR, HPA, clipping filtering, CCDF

\section{INTRODUCTION}

Communication services are currently a necessity for telecommunications field services. Communication with data is a communication service that requires broadband to be sent and received quickly [1]. The services desired by the community is a system with productive performance on access speed and efficiency in bandwidth usage [2]. This can take advantage of an Orthogonal Frequency Division Multiplexing (OFDM) system. In operation, the transmission system uses several frequencies (multi carriers) which are mutually perpendicular (orthogonal) [3]. The frequency used has high efficiency and is strong in resisting the presence of frequency selective fading. In addition, the OFDM system in transmitting is not very sensitive to the occurrence of delay [4]. Wireless communication standards experience different principles, for example in the standard of IEEE 802.11a on Wireless Local Area Network (WLAN) [5]. The OFDM transmission method does not place every sub-carrier based on the available bandwidth. The sub-carriers arrange to overlap each other. The characteristic of orthogonality between the sub-carrier arrangement is therefore referred to as OFDM[6]. Using overlapping arrangement techniques can save about 50\% bandwidth. The weakness of OFDM is high non-linear distortion in high power amplifier (HPA) devices [7]. This distortion causes a decrease in the bit error rate and out-of-band radiation. The high PAPR value is caused by the modulation of each subcarrier in the presence of different frequencies. This results in several sub-carriers having a coherent phase with the appearance of amplitude with a level much greater than the signal power [8]. To obtain the linearization process of the High-Power Amplifier, various research methods were carried out including Partial Transmit Sequence (PTS), Coding, Interleaving and Peak Windowing, Selected Mapping and Clipping Filtering. The clipping technique is one of the simplest PAPR reductions, namely the amplitude signal at the maximum level required. Clipping of the input signal is carried out before entering the amplifier [9]. Getting the highest peak signal has a small value, so clipping techniques are effective for reducing PAPR. OFDM signal peak power is limited with a threshold as the maximum value during the clipping process. The weakness of the clipping technique produces power distortion (clipping noise) so that the spectrum signal widens which causes interference. As a form of suppressing these weaknesses, it is combined with filtering techniques as a reduction spectrum. Combining clipping and filtering can suppress the signal or reduce the spectrum beyond the bandwidth. Besides that, it can also reduce the signal at the clip level limit. With a combination of clipping and filtering techniques, it gives an increase in the peak of the signal that exceeds the clip level, so that the iteration process can be repeated. The purpose of this research is to reduce the Clipping Filtering technique with the value of the clipping ratio (CR) to produce the PAPR0 value, through the CCDF (Complementary Cumulative Distribution Function) curve. 


\section{International Advanced Research Journal in Science, Engineering and Technology}

Vol. 8, Issue 10, October 2021

\section{DOI: $10.17148 /$ IARJSET.2021.81034}

\section{RESEARCH METHODS}

The research method used in this study is based on the OFDM system parameters on mobile wireless communication. The primary data is taken theoretically based on the Standards of the International Telecommunication Union (ITU). The utilization of software from MATLAB is used as a test parameter for the results of the analyzed data. The primary data used in this study is a standard wireless communication, namely the number of subcarriers of $\mathrm{N}=512$, the modulation used is 16 QAM [10]. Based on the constellation diagram one symbol for 16 QAM modulation consists of four bits. While the number of input bits is 10000 bits per iteration. The secondary data is based on the linearization area curve and the BER curve to the SNR. Observation of data results with clipping filtering technique from the use of power amplifiers. The clipping filtering method is effective in reducing PAPR by eliminating signal components that exceed the clip level [11]. When the amplitude exceeds the input, signal is cut off at a certain level. However, the weakness in this method is that it produces power distortion, or what is known as clipping noise and widens the signal spectrum and causes interference. To obtain maximum results, this clipping technique is combined with filtering techniques to reduce the spectrum. This combination of clipping and filtering techniques is effective in removing spectrum components outside the signal bandwidth and reducing signal amplitude beyond the clip level. The system clipping filtering block is as shown in Figure 1.

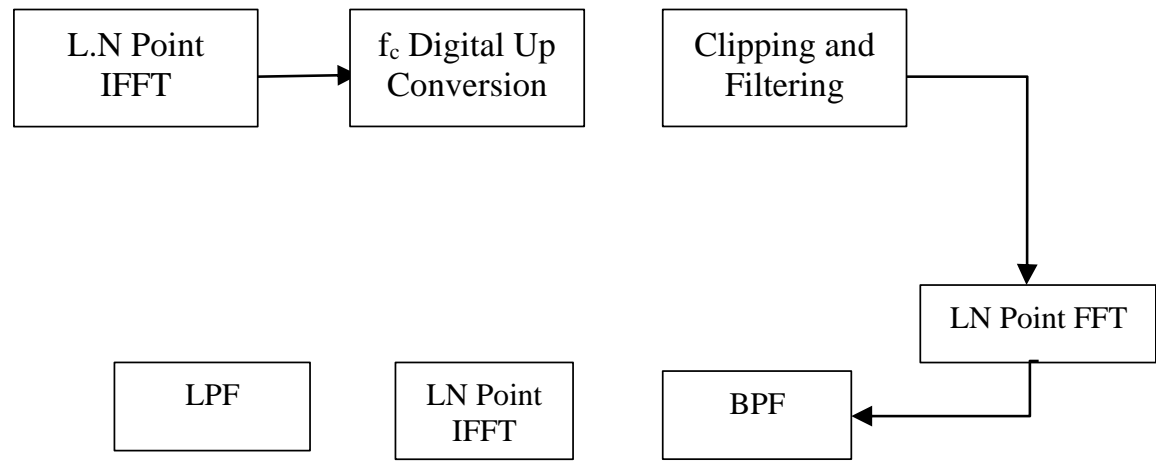

Figure 1. Block Diagram Clipping and Filtering

Based on Figure 1 block of clipping and filtering reduction techniques, the value of $\mathrm{N}$ indicates the number of subcarriers and $\mathrm{L}$ as the oversampling factor. In the diagram, IFFT produces $\mathrm{X}^{\prime}(\mathrm{m})$ which is an oversampled L-times signal. Then the FFT-IFFT filter allows the signal to pass through a band current filter (BPF) and then through a low-pass filter (LPF). This combination of clipping and filtering techniques is effective in removing components from the spectrum that exceed the clip level. Although the filtering process after clipping can reduce out-band radiation. However, it also causes some peak regrowth that exceeds the clip level. The original OFDM signal is not affected by the clipping and filtering process as shown in Figure 2.

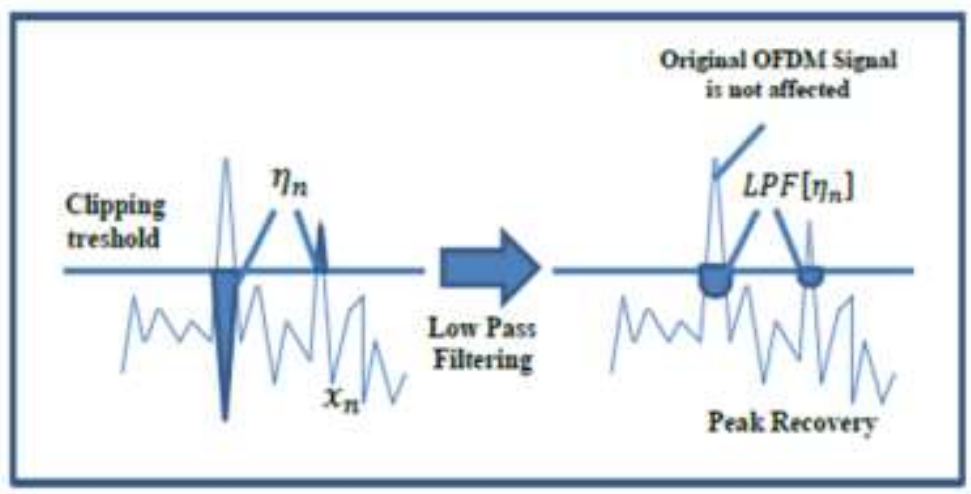

Figure 2. Mechanism of Peak Regrowth Clipping Filtering Technique

Based on the schematic of Figure 2, the discrete signal is oversampled L-times of $x^{\prime}(\mathrm{m})$ from the IFFT filter, then modulated with a carrier frequency fc to produce a passband signal XP(m). The XP c $(\mathrm{m})$ signal is the result of clipping $\mathrm{XP}(\mathrm{m})$ signal so that the limits applied to the baseband signal as a complex value signal are also real value passband signals. The provisions that are made for the peak power of the OFDM signal with the threshold limit of the following equation, 


\section{International Advanced Research Journal in Science, Engineering and Technology}

Vol. 8, Issue 10, October 2021

\section{DOI: $10.17148 /$ IARJSET.2021.81034}

$$
\begin{array}{r}
\hat{x}(n)=\left\{\begin{array}{l}
A_{\text {max }} e^{j \varphi t},|x(n)|>A_{\text {max }} \\
x(n), \quad|x(n)| \leq A_{\text {max }}
\end{array}\right. \\
\varphi t=\arg [\hat{x}(n)
\end{array}
$$

From the equation above, a signal whose amplitude does not exceed $\mathrm{A}_{\max }$ or clipping level is the same as the original phase. Clipping level or threshold is the maximum value of the signal that will be passed and then sent to the channel. The value of $\mathrm{A}$ is determined by the Clipping Ratio (CR) parameter. The smaller the value of the clipping ratio, the more parts of the signal are cut so that it will produce a low PAPR value. The clipping block is calculated as the average value, variance and standard deviation of the clipping level(A) search. This means that clipping is the maximum value of the signal that is passed and then sent to the channel. The search for clipping level (A) is as follows,

$A=C R X \sigma$

Based on the equation of the clipping level, $\mathrm{CR}$ is the clipping ratio as the value for the cut signal. The smaller the value of the clipping ratio means the more signals are cut off. The deviation level $(\sigma)$ with the rms level of the OFDM signal with the following calculation game,

$$
\sigma=\sqrt{\frac{N}{2}}
$$

Provided that, $\sigma$ is the rms level of the OFDM signal (volts), while $\mathrm{N}$ is the number of subcarriers. After going through the reduction process, the results of the reduction can be observed from the CCDF curve by calculating the equation using the PAPR equation as follows,

With,

$$
P A P R=\frac{P_{\text {peak }}}{P_{\text {average }}}=\frac{\max |x(n)|^{2}}{E\left(|x(n)|^{2}\right)}
$$

$$
\begin{array}{ll}
P_{\text {peak }} & =\text { maximum power }(\text { Watt }) \\
P_{\text {average }} & =\text { average power }(\text { Watt) } \\
\max |x(n)|^{2} & =\text { peak OFDM signal after reduction (Watt) } \\
E\left(|x(n)|^{2}\right) & =\text { average OFDM signal after reduction (Watt) }
\end{array}
$$

Based on the $1.25 \mathrm{~kW}$ SuperLinear TWT Amplifier datasheet, with specifications for Supply Voltage $\pm 200 \mathrm{~V}_{\mathrm{ac}}$, Supply Current 15.0 Amp, Power Output 540 W Min and using a Class C Power Amplifier (PA) is an amplifier that has high efficiency of $80 \%$ and is the most suitable applied in Radio Frequency. From these specifications, the PAPR value acquired using the following equation:

$$
\begin{aligned}
& P A P R_{x}=\frac{0.8 P_{d c}}{P_{\text {out }}}=\frac{0.8 \times V d c \times I d c}{P_{\text {out }}}=\frac{0.8 \times 200 \times 15}{540}=4,4 \\
& P A P R_{d B}=10 \log 4,4=6,4 \mathrm{~dB}
\end{aligned}
$$

The calculation result is the limit of the PAPR value that is allowed to pass through the High Power Amplifier where we have to cut the signal at least until the PAPR value is equal to or less than the predetermined value. The calculation value as a function of SNR with comparison parameters in the form of changes in modulation level, channel differences, and clip depth \& threshold values. Bit Error Rate (BER) is the ratio of the number of incorrect bits received by the receiver to the number of bits sent. In reality, BER is strongly influenced by noise because noise can cause an error in the detection process. One of the BER parameters is SNR (Signal to Noise Ratio) which is the ratio of signal strength to the percentage of noise. The greater the SNR, the better the performance of the voice coding system. BER is calculated in the following equation:

$$
B E R=\frac{\mid \text { Bit input }- \text { Bit output } \mid}{\text { number of bits }}
$$

Calculation of Bit Error Rate (BER) based taken on the number of input bits and output bits. This comparison finds out the value of BER along 20 Signal to Noise Ratio. 


\section{International Advanced Research Journal in Science, Engineering and Technology}

Vol. 8, Issue 10, October 2021

\section{DOI: $10.17148 /$ IARJSET.2021.81034}

\section{III.RESULTS AND DISCUSSION}

Based on the linearization testing process of High-power Amplifier (HPA) with PAPR reduction techniques, clipping and filtering types, there are results with the following stages,

1. Clipping and filtering tests to determine the minimum value of PAPR reduction in the form of a curve CCDF (Complementary Cumulative Distribution Function).

2. The value of the clipping ratio (CR) has been determined in advance.

3. The data used from binary data 10000 bits is generated randomly with the randint command, then with 1250 characters are converted to 8 bits per character so the total is 10000 bits. This value of 10000 bits is used for the input OFDM system. However, plotting them uses 100 bits to make it easier to analyze.

The results obtained from the random input signal generated from 16-QAM modulation, the bits that have been generated are modulated. 16-QAM modulation with $\mathrm{M}=16$ means $2 \mathrm{~m}=16$ so that each 16-QAM modulation symbol consists of 4 bits. From IFFT there is a domain process by changing the frequency to the time domain. The signal is converted in parallel $\mathrm{N}$ conversion. The value of $\mathrm{N}$ is the IFFT size. This study uses 512 IFFT sizes. Furthermore, the signal amplitude is observed with a maximum value to determine the Clipping Ratio (CR) variable for clipping filtering. Figure 3 shows the results of clipping and filtering for $\mathrm{CR}=4$ through the IFFT process.

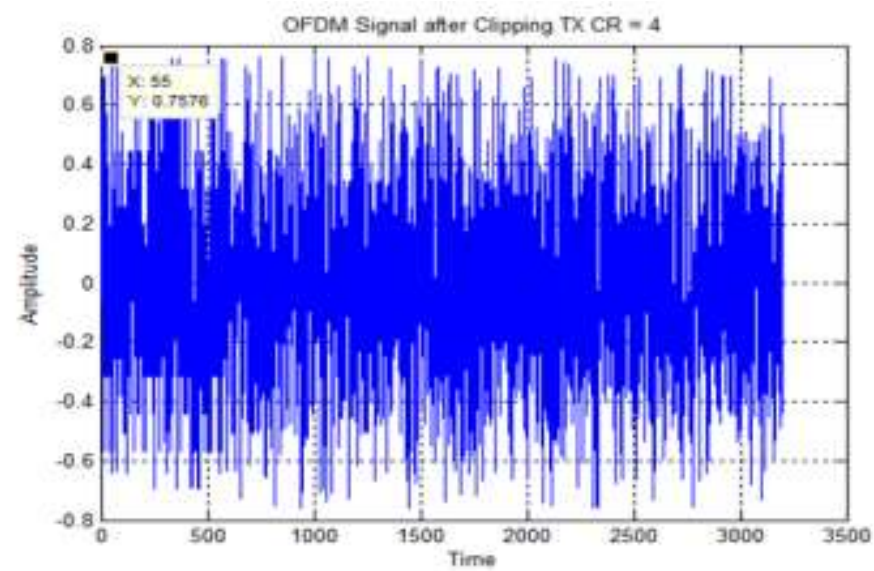

Figure 3. Clipping Filtering Results $\mathrm{CR}=4$

The time-domain signal with the maximum amplitude is PAPR, so it is necessary to cut the amplitude using a variable Clipping Ratio (CR). The maximum clipping filtering amplitude is 0.9672, but after lipping filtering the maximum amplitude is 0.7576 by setting $\mathrm{CR}=4$, the truncated amplitude is 0.2096 . By adding a Power Amplifier the signal is amplified resulting in the emergence of PAPR.

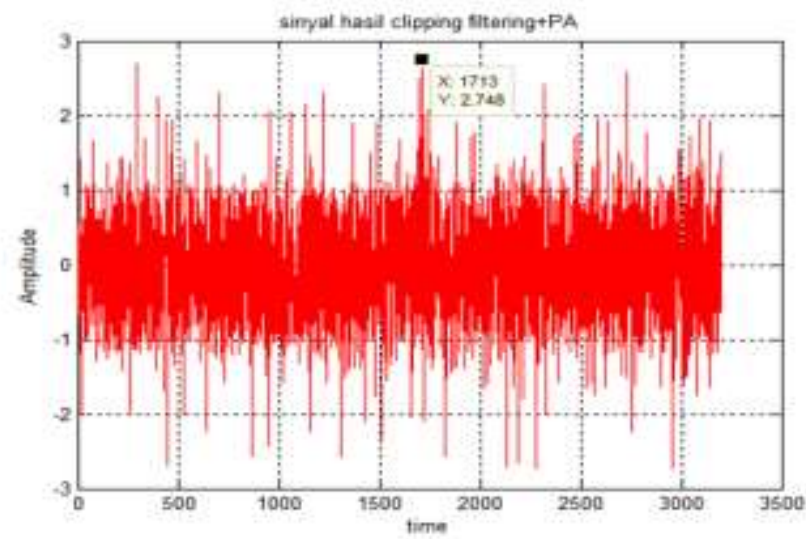

Figure 4. Signal Result of Clipping Filtering with Addition of Power Amplifier (PA)

With the addition of Power Amplifier maximum amplitude of 0.7576 after passing the Power Amplifier (PA) the signal is amplified again to 2.748 so that PAPR occurs. Furthermore, testing the clipping filtering reduction technique with variable clipping ratio (CR) by utilizing the CCDF curve. From the OFDM signal curve, the results of Clipping Filtering are reduced with several different $C R$ values. 


\section{International Advanced Research Journal in Science, Engineering and Technology}

Vol. 8, Issue 10, October 2021

\section{DOI: $10.17148 /$ IARJSET.2021.81034}

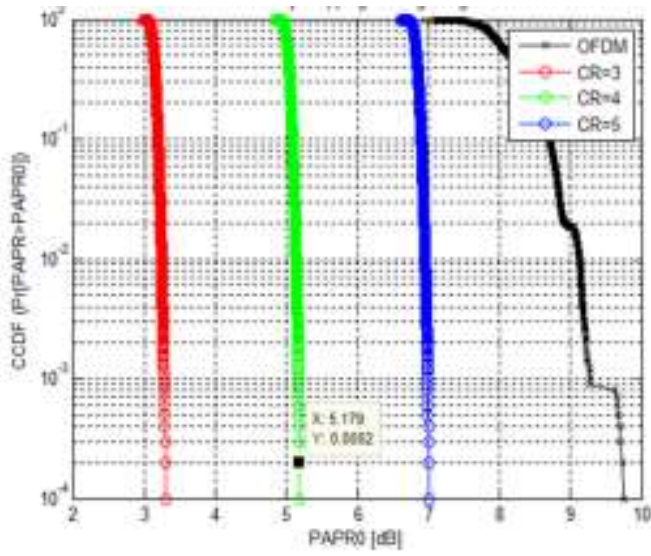

Figure 5. OFDM Performance in Clipping Filtering Techniques PAPR Reduction Variable Clipping Ratio(CR)

Based on the results of the OFDM result curve the results of the Clipping Filtering reduction. The red curve of the OFDM signal CCDF after reducing Clipping Filtering with $\mathrm{CR}=3$, the green colour shows the CCDF Clipping Filtering signal with $\mathrm{CR}=4$, the blue colour shows the CCDF Clipping Filtering signal with $\mathrm{CR}=5$, and the black colour indicates the original OFDM signal CCDF. In this test, observations were made on the probability of PAPR $>$ PAPR0 $=10-4$ or the smallest possible of 10,000 peak voltages of the OFDM symbol. The results of the probability PAPR > PAPR0 of 10-4 on the OFDM transmitter system without reduction (OFDM) produces a PAPR0 value of $9.727 \mathrm{~dB}$. Then by using the Clipping Filtering reduction technique with a value of $\mathrm{CR}=5$, it produces a PAPR0 value of $7.003 \mathrm{~dB}$, so that it can be seen that its performance can reduce PAPR0 by $2.724 \mathrm{~dB}$ with a signal reduction effectiveness of $71.99 \%$. Clipping Filtering with a value of $\mathrm{CR}=4$ produces a PAPR0 value of $5.179 \mathrm{~dB}$ so that it can be seen that its performance can reduce PAPR0 by 4.548 . dB with 53.24\% signal reduction effectiveness. Furthermore, for the Clipping Filtering reduction technique with a value of $\mathrm{CR}=3$, it produces a PAPR0 value of $3.279 \mathrm{~dB}$ so that it can be seen that its performance can reduce PAPR0 by $33.71 \mathrm{~dB}$ with reduced signal effectiveness of $33.71 \%$. So this value of $\mathrm{CR}=4$ is used as a parameter before entering the Power Amplifier because according to the calculations on the $1.25 \mathrm{~kW}$ Super Linear TWT Amplifier datasheet the minimum allowed PAPR value is $5.18 \mathrm{~dB}$.

\section{IV.CONCLUSION}

The results of the study using Clipping Filtering to determine the minimum value of PAPR reduction in the form of a CCDF (Complementary Cumulative Distribution Function) curve with a predetermined Clipping Ratio (CR) value parameter, the results of observing the probability of PAPR > PAPR0 are 10-4 on an OFDM transmitter system without reduction. (OFDM) produces a PAPR0 value of $9.727 \mathrm{~dB}$. Then by using the Clipping Filtering reduction technique with a value of $\mathrm{CR}=5$, it produces a PAPR0 value of $7.003 \mathrm{~dB}$, so that it can be seen that its performance can reduce PAPR0 by $2.724 \mathrm{~dB}$ with a signal reduction effectiveness of $71.99 \%$. Clipping Filtering with a value of CR $=4$ produces a PAPR0 value of $5.179 \mathrm{~dB}$ so that it can be seen that its performance can reduce PAPR0 by $4.548 \mathrm{~dB}$ with a signal reduction effectiveness of 53.24\%. Furthermore, for the Clipping Filtering reduction technique with a value of $\mathrm{CR}=3$, it produces a PAPR0 value of $3.279 \mathrm{~dB}$ so that it can be seen that its performance can reduce PAPR0 by $33.71 \mathrm{~dB}$ with a signal reduction effectiveness of $33.71 \%$. The value of $\mathrm{CR}=4$ as a parameter before entering the Power Amplifier because according to the calculations in the $1.25 \mathrm{~kW}$ Super Linear TWT Amplifier datasheet the minimum allowed PAPR value is $5.18 \mathrm{~dB}$.

\section{REFERENCES}

[1] A.F.S,Admaja1, and S. Ariyanti, "Wireless Gigabit untuk Komunikasi Pita lebar Broadband communication in Wireless Gigabit," Buletin Pos dan Telekomunikasi, Vol.14(2), pp.65-78,2016

[2] E. Ruth, "Deskripsi Kualitas Layanan Jasa Akses Internet di Indonesia dari Sudut Pandang Penyelenggara Description of Internet Quality of Services (Qos) in Indonesia From the Providers' Point of View," Buletin Pos dan Telekomunikasi, Vol.1(2) ,pp. 137-146,2013

[3] Hasan, Suwadi, T.Suryani, "Implementasi dan Evaluasi Kinerja Orthogonal Frequency Division Multiplexing (OFDM) Menggunakan WARP," JURNAL TEKNIK ITS Vol.4(1), pp.119-124, 2015

[4] B.B, Harianto "Pengukuran Kinerja Orthogonal Frequency Division Multiplexing (OFDM) Pada Sbx Doughter Board Menggunakan Labview dan USRP N-210,'”https://ejournal.poltekbangsby.ac.id, 2019

[5] Paryati, "Pemanfaatan Teknologi Wimax Dan Wibro Untuk Mengoptimalkan Komunikasi Dalam Bidang Industri," Seminar Nasional Informatika, pp. 51-59, 2012

[6] M.F. Sugita, R. Hidayat, S.S.Kusumawardhani, A. Karnik, "Reduksi Peak to Average Power Ratio (PAPR) Menggunakan Teknik Clipping," JNTETI, vol.1(1), pp.49-54, ,2012 
International Advanced Research Journal in Science, Engineering and Technology

Vol. 8, Issue 10, October 2021

\section{DOI: $10.17148 /$ IARJSET.2021.81034}

[7] I. Anisah, Y. Moegiharto, M.Ridwan, I.H. Idfira, “Analisa Kinerja Teknik Reduksi PAPR Metode SLM dan HPA Predistorsi dengan Pemodelan Hammerstein pada Sistem OFDM,” Journal of Computer, Electronic, and Telecommunication,vol.1(2), pp.1-10, 2019

[8] R.H, Subrata, and F.Gozali, "Simulasi Teknik Modulasi OFDM QPSK Dengan Menggunakan Matlab," JETri, Vol.12(2), pp.1-18, 2015

[9] A.N,Azizah ,dan I. S,Rohma, "Pembuatan Model Hybrid 2 Teknik Reduksi Peak-To-Average Power Ratio Partial Transmit Sequence Dan Clipping Filtering Pada Sistem Mimo-Ofdm," Prosiding SNATIF Ke -4 Tahun, 2017

[10] Sabrina, A. A, Muayyadi, L. Meylani, “Reduksi PAPR Menggunakan Coded PTS Pada Sistem MiMo OFDM 8 X 8," e-Proceeding of Engineering, vol.3(2), pp. 1725-1736,2016

[11] D.T,Aksara, A.B,Satriya, D,Setiabudi, “Analisa Perbandingan BER dan PAPR dalam Transmisi Citra pada Sistem 4G LTE,” Jurnal Arus Elektro Indonesia,vol.3(1), pp.16-21,2017 